\title{
DETERMINATION OF AIR-BORNE TRINITROTOLUENE, TETRYL AND DINITROTOLUENE
}

\author{
BY
}

\author{
W. M. CUMMING and W. G. D. WRIGHT
}

From the Royal Technical College, Glasgow

Since the commencement of the present war, a number of methods have been described for the estimation of airborne TNT (2:4:6 trinitrotoluene), by Kay (1941), Pinto and Fahy (1942), Goldman and Rushing (1943) and Cone (1943).

With a view to producing a simple and portable system which could be readily used by an inexperienced worker and might be expected to give accurate results, we have developed a method which, in a broad sense, is based on that of Kay. Kay's method is a colorimetric one dependent on the red colour developed by the action of caustic alkali on TNT in acetone solution. The air containing TNT is drawn through 150 c.c. of acetone: aliquot portions of this solution are treated with alkali and the quantity of TNT present estimated by the intensity of the red colour produced. The colour is stated to be unstable after about 30 minutes.

The main idea of our method has been to produce the colour in situ in a bubbling tube and compare directly with standards. For such a method, acetone is not suitable, partly because of its volatility and partly because of the instability of the colour produced with alkali.

After trial with a large variety of solvents of a less volatile nature, the most suitable was found to be cyclohexanone. This solvent is relatively non-volatile (b.p. $156^{\circ} \mathrm{C}$.) and gives an intense red colour when dissolved TNT is treated with alkali. This red colour is very stable and can be kept for a week without fading. The only outstanding disadvantage is the sparing solubility of the alkali in cyclohexanone and it is necessary to shake the cyclohexanone and alkali solution together very thoroughly before apparent interaction between the TNT and alkali takes place. It is possible, however, to increase the mutual solubilities of the alkali and solvent by using a mixture of cyclohexanone and methylethylketone (b.p. $80^{\circ}$ C.), the latter being less volatile than acetone and yet possessing miscibility with water. The colour produced in this solution is intense and permanent and conforms to Beer's Law and is therefore suitable for this estimation.

In an exactly similar way, a quantitative colour can be produced with tetryl ( $2: 4: 6$ trinitrophenyl-1methylnitramine); in this case, the colour is of a brownish-red and is not quite so stable as with TNT.

Channon, Mills and Williams (1944) have recently published a list of the colours produced by a number of nitro compounds when treated with this reagent.

With the collaboration of The Tintometer, Ltd., discs have been prepared for TNT and tetryl, affording a range of nine permanent standards for each compound. A description of the method for estimation of TNT and tetryl follows. This method has been employed with success over a period of two years.

\section{A. Method For TNT AND Tetryl}

Apparatus

The accompanying photographs '(Figs. 1 and 2) show the apparatus employed.

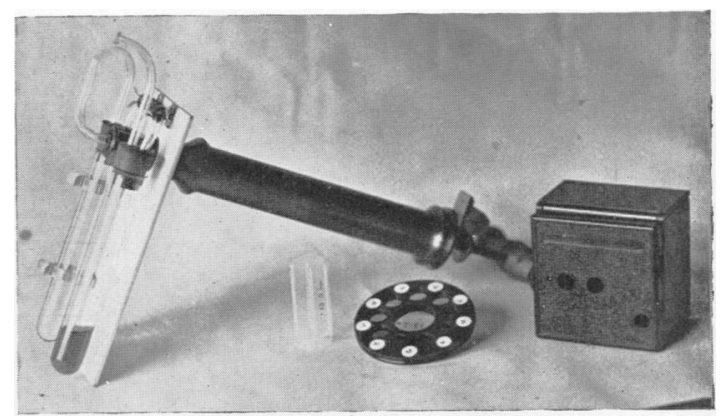

FIG. 1.-Assembled pump equipment, Tintometer, disc and cell.

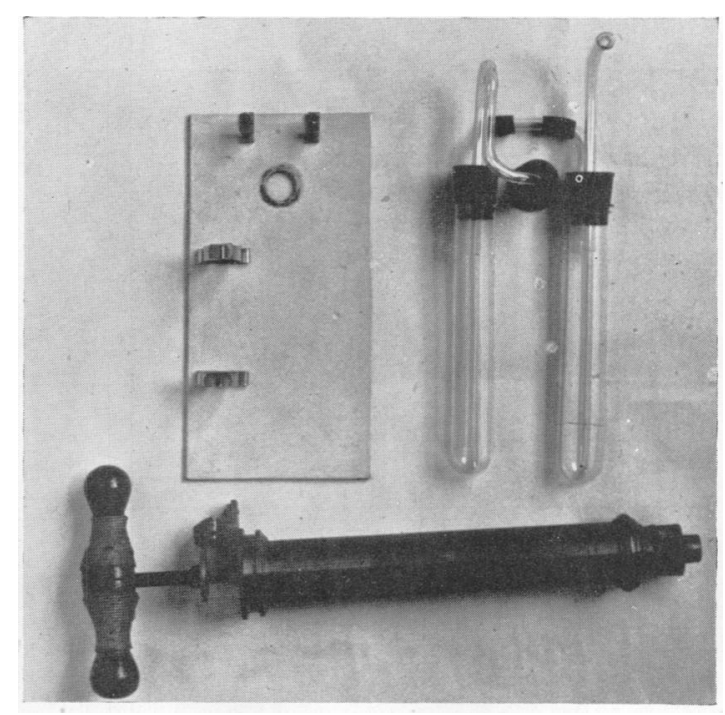

FIG. 2.-Dismantled pump equipment.

(a) Pump. This is the standard pump designed by the Department of Scientific and Industrial Research for the estimation of toxic gases in industry. The capacity of this pump is $125 \mathrm{ml}$. per stroke. It is fitted with a stroke counter

(b) Tube Mounting. On the inlet of the pump is mounted a thin board painted white, 8 in. by 4 in., which carries the trap, sampling tube and air inlet. This is easily dismantled for transport as all the tubing is fixed by spring clips.

This board is screwed between the main inlet valve-holder of the pump and the adaptor. The tubing for connection to the bubbler system is fitted to the adaptor. It is essential to have washers on either side of the board to give a gastight joint.

(c) Tubing. All tubing zonnections are made of glass, and the bubbler tubes are of 0.75 in. internal diameter by 6 in. long, having a graduation mark at $10 \mathrm{ml}$. 
The air inlet tube has an overall length of 10 in. drawn out to a jet which just allows a wire of 24 S.W.G. to pass. Its upper end is curved with a radius of $1 \frac{1}{2} \mathrm{in}$. and terminates at 90 degrees to the tube. This design is to minimize the amount of dust deposited in the tube.

(d) Tintometer. The instrument is the All-purposes Lovibond Comparator. The cells are of $13.5 \mathrm{~mm}$. internal width, having plane faces, and side walls of frosted glass.

\section{Standard Colours}

The standard colours have been carefully chosen to cover a useful working range. On the Tintometer disc these colours are numbered 1 to 9 and correspond to the concentrations of TNT and tetryl recorded in Table 1 when using a cell of $13.5 \mathrm{~mm}$. thickness.

Tables 2 and 3 correlate the number of strokes on the D.S.I.R. pump with the standard colour produced and give the results in milligrams of TNT or tetryl per cubic metre of air.

TABLE 1

\begin{tabular}{|c|c|c|}
\hline \multirow{2}{*}{$\begin{array}{l}\text { Standard } \\
\text { numbers } \\
\text { on discs }\end{array}$} & \multicolumn{2}{|c|}{$\begin{array}{l}\text { Concentration in mg./litre solvent } \\
\text { (for cell } 13.5 \mathrm{~mm} \text {. thick) }\end{array}$} \\
\hline & TNT & Tetryl \\
\hline $\begin{array}{l}1 \\
2 \\
3 \\
4 \\
5 \\
6 \\
7 \\
8 \\
9\end{array}$ & $\begin{array}{c}1 \cdot 575 \\
2 \cdot 36 \\
3 \cdot 15 \\
4 \cdot 73 \\
6 \cdot 30 \\
7 \cdot 87 \\
9 \cdot 45 \\
11 \cdot 0 \\
12 \cdot 6\end{array}$ & $\begin{array}{c}3 \cdot 15 \\
4 \cdot 72 \\
6 \cdot 30 \\
9 \cdot 46 \\
12 \cdot 6 \\
15 \cdot 75 \\
18 \cdot 9 \\
22 \cdot 0 \\
25 \cdot 2\end{array}$ \\
\hline
\end{tabular}

N.B. The above table holds for solutions of TNT in acetone (Kay method) provided comparison is made with the standards immediately after the colour is produced; otherwise, fading of the colour interferes with the estimation.

TABLE 2

MILLIGRAMS TNT/CUBIC METRE FOR SOLUTION THICKNESS, 13.5 MM. AND PUMP CAPACITY $125 \mathrm{ML}$.

\begin{tabular}{|c|c|c|c|c|c|c|c|c|c|}
\hline \multirow{2}{*}{$\begin{array}{c}\text { Number } \\
\text { of } \\
\text { strokes }\end{array}$} & \multicolumn{9}{|c|}{ Colour standard } \\
\hline & 1 & 2 & 3 & 4 & 5 & 6 & 7 & 8 & 9 \\
\hline $\begin{array}{r}10 \\
15 \\
20 \\
30 \\
40 \\
50 \\
60 \\
75 \\
100 \\
125\end{array}$ & $\begin{array}{c}13 \cdot 0 \\
9 \cdot 0 \\
6.0 \\
5 \cdot 0 \\
3 \cdot 0 \\
2.5 \\
2.1 \\
1.9 \\
1.25 \\
1.0\end{array}$ & $\begin{array}{r}19 \cdot 0 \\
14 \cdot 0 \\
9.0 \\
7 \cdot 0 \\
5 \cdot 0 \\
4 \cdot 0 \\
3 \cdot 2 \\
2 \cdot 8 \\
1.9 \\
1 \cdot 5\end{array}$ & $\begin{array}{r}25.0 \\
19.0 \\
13.0 \\
9.0 \\
6.0 \\
5.0 \\
4.2 \\
3.8 \\
2.5 \\
2.0\end{array}$ & \begin{tabular}{|c|}
38.0 \\
28.0 \\
19.0 \\
14.0 \\
9.0 \\
7.5 \\
6.3 \\
5.7 \\
3.75 \\
3.0
\end{tabular} & \begin{tabular}{r|}
500 \\
38.0 \\
25.0 \\
19.0 \\
12.0 \\
10.0 \\
8.4 \\
7.6 \\
5.0 \\
4.0
\end{tabular} & \begin{tabular}{|c|}
63.0 \\
47.0 \\
31.0 \\
23.0 \\
16.0 \\
13.0 \\
10.7 \\
9.3 \\
6.25 \\
5.0
\end{tabular} & \begin{tabular}{|r|}
75.0 \\
56.0 \\
38.0 \\
28.0 \\
19.0 \\
15.0 \\
13.0 \\
11.0 \\
7.5 \\
6.0
\end{tabular} & \begin{tabular}{|c|}
88.0 \\
66.0 \\
44.0 \\
33.0 \\
22.0 \\
18.0 \\
15.0 \\
13.0 \\
8.75 \\
7.0
\end{tabular} & $\begin{array}{l}100 \\
75 \\
50 \\
38 \\
25 \\
20 \\
17 \\
15 \\
10 \\
8\end{array}$ \\
\hline
\end{tabular}

These tables hold only so long as the pump capacity is $125 \mathrm{ml}$., but as the concentration of TNT and tetryl for each coloured standard is given in Table 1 in milligrams of TNT or tetryl per litre of solution, the figures giving airborne concentrations can be recalculated to suit a pump of a different capacity.

\section{Solutions}

(a) Solvent. The solvents used must be of high purity. They are redistilled using an eight-bulb fractionation column

(1) Cyclohexanone-fraction b.p. $154-156^{\circ} \mathrm{C}$. is retained.

(2) Methyl ethyl ketone-fraction b.p. $79^{\circ}-80^{\circ}$ C. is retained.
TABLE 3

MILLIGRAMS TETRYL/CUBIC METRE FOR SOLUTION THICKNESS, 13.5 MM. AND PUMP CAPACITY $125 \mathrm{ML}$.

\begin{tabular}{|c|c|c|c|c|c|c|c|c|c|}
\hline \multirow{2}{*}{$\begin{array}{c}\text { Number } \\
\text { of } \\
\text { strokes }\end{array}$} & \multicolumn{9}{|c|}{ Colour standard } \\
\hline & 1 & 2 & 3 & 4 & 5 & 6 & 7 & 8 & 9 \\
\hline $\begin{array}{r}10 \\
15 \\
20 \\
30 \\
40 \\
50 \\
60 \\
75 \\
100 \\
125 \\
150 \\
200 \\
250\end{array}$ & $\begin{array}{r}26.0 \\
18.0 \\
12.0 \\
10.0 \\
6.0 \\
5.0 \\
4.2 \\
3.8 \\
2.5 \\
2.0 \\
1.6 \\
1.3 \\
1.0\end{array}$ & \begin{tabular}{r|}
38.0 \\
28.0 \\
18.0 \\
14.0 \\
10.0 \\
8.0 \\
6.4 \\
5.6 \\
3.8 \\
3.0 \\
2.4 \\
2.0 \\
1.5
\end{tabular} & \begin{tabular}{r|}
50.0 \\
38.0 \\
26.0 \\
18.0 \\
12.0 \\
10.0 \\
8.4 \\
7.6 \\
5.0 \\
4.0 \\
3.2 \\
2.6 \\
2.0
\end{tabular} & $\begin{array}{r}76 \cdot 0 \\
56 \cdot 0 \\
38.0 \\
28.0 \\
18.0 \\
15.0 \\
12.6 \\
11.4 \\
7.5 \\
6 \cdot 0 \\
4.8 \\
4.0 \\
3.0\end{array}$ & $\begin{array}{r}100.0 \\
76.0 \\
50.0 \\
38.0 \\
24.0 \\
20.0 \\
16.8 \\
15.2 \\
10.0 \\
8.0 \\
6.4 \\
5.2 \\
4.0\end{array}$ & $\begin{array}{r}125.0 \\
94.0 \\
62.0 \\
46.0 \\
32.0 \\
26.0 \\
21.5 \\
18.5 \\
12.5 \\
10.0 \\
8.2 \\
6.6 \\
5.0\end{array}$ & $\begin{array}{r}150 \\
112 \\
76 \\
56 \\
38 \\
30 \\
26 \\
22 \\
15 \\
12 \\
10 \\
8 \\
6\end{array}$ & $\begin{array}{r}175.0 \\
132.0 \\
88.0 \\
66.0 \\
44.0 \\
36.0 \\
30.0 \\
26.0 \\
17.5 \\
14.0 \\
11.0 \\
9.0 \\
7.0\end{array}$ & $\begin{array}{r}200 \\
150 \\
100 \\
76 \\
50 \\
40 \\
34 \\
30 \\
20 \\
16 \\
12 \\
10 \\
8\end{array}$ \\
\hline
\end{tabular}

Equal volumes of the solvents are mixed and stored in a dark bottle. This mixed solvent should be a water-clear liquid.

(b) Alkali. Twelve grams of pure potassium hydroxide are dissolved in distilled water and made up to 100 c.c. This is kept in a bottle fitted with a dropping pipette, this being graduated to deliver 0.5 c.c. of alkali solution.

\section{Procedure}

To a sampling tube solvent is added up to the $10 \mathrm{ml}$. graduation mark. This is followed by 0.5 c.c. of the $\mathrm{KOH}$ solution. The tube is shaken vigorously for 2 minutes so as to distribute thoroughly the alkali in the solvent and is then attached to the pump, which is operated at about 1 stroke in 5 seconds.

Bubbling is commenced in the atmosphere to be sampled and is continued until a distinct colour develops. The tube is removed and shaken again for 1 minute, suspended alkali is allowed to settle out for another minute and the contents of the tube then poured into a Tintometer cell $13.5 \mathrm{~mm}$. wide and the colour matched off in the Tintometer against the standard disc.

From the number of strokes taken and the colour standard obtained on the appropriate disc, a direct reading of the concentration of the airborne material, TNT or tetryl, can be obtained from Tables 2 or 3 .

\section{Note on Tetryl Estimation}

As the tetryl colour tends to fade, the test must be carried out without delay and, when the number of strokes to give a colour is large (of the order of 100), it is advantageous to use the solvent alone and then to add alkali after bubbling and compare colour produced.

\section{B. Method for DNT ( $2: 4$ Dinitrotoluene)}

The above method for TNT and tetryl is not applicable to the estimation of DNT. The method adopted for DNT is based on the absorption of the DNT by a naphthalene filter (Briscoe, 1939), followed by the solution of the naphthalene in a mixed solvent of acetone and cyclohexanone with subsequent addition of alkali and the formation of a blue colour due to $2: 4$ DNT. Pure 2:6 DNT which usually occurs in association with $2: 4$ DNT in the dinitration product of mononitrotoluene to about 20 per cent. gives no colour with alkali. The blue colour which is produced with $2: 4$ DNT develops slowly and is unstable. It was not found possible to stabilize or accelerate the colour change.

With acetone a royal blue colour is produced, with cyclohexanone a violet blue, and with methyl ethyl ketone a violet colour, the latter developing only very slowly.

It was decided to use a mixture of 90 per cent. acetone with 10 per cent. cyclohexanone as this gave a blue colour which reached a suitable maximum shade after 10 minutes. This colour was satisfactorily matched against aqueous solutions of Gentian violet as standards. 
Solutions

(a) Solvent. The solvent used throughout is a mixture of 10 per cent. cyclohexanone and 90 per cent. acetone by volume.

The cyclohexanone is purified by distillation, b.p. $154^{\circ}-$ $156^{\circ}$ C.: acetone, b.p. $56^{\circ} \mathrm{C}$.

(b) Alkali. Twelve grams of pure potassium hydroxide is dissolved in distilled water and made up to 100 c.c.

\section{Naphthalene}

This must be pure and should give no colour with alkali when dissolved in acetone. It may be necessary to sublime the naphthalene in order to obtain a pure product, m.p. $=80^{\circ} \mathrm{C}$. This is now finely ground and placed in a stoppered bottle.

\section{Standard Colours}

Four solutions of 2:4 DNT in the solvent are made up so as to contain respectively (i) 0.03125 , (ii) 0.0625 , (iii) 0.09325 , and (iv) 0.125 milligrams of DNT per 100 c.c., diluting appropriately to obtain the solutions above.

To 10 c.c. of each of these is added 0.5 c.c. of the $\mathrm{KOH}$ solution and the tubes shaken thoroughly. On the expiry of 10 minutes after the addition of the alkali, the blue colours produced are matched by aqueous solutions of Gentian violet. These latter standards are numbered 1 to 4 and are retained in well corked tubes 6 in. long by 0.75 in. internal diameter. They are stable for several weeks but should be rematched from time to time.

\section{Apparatus}

The standard D.S.I.R. pump is used, but instead of carrying the tubing and bubblers, a small No. 1 sintered glass micro filter $12 \mathrm{~mm}$. diameter and about $30 \mathrm{~mm}$. long is attached by insertion in a rubber stopper fitted into the nozzle of the pump. A filter pad of naphthalene is made by using $0.4-0.5 \mathrm{gm}$. of the ground material. The naphthalene is firmly pressed down on to a disc of filter paper resting on the sintered surface. The naphthalene filter is prepared in this way before entering the atmosphere to be tested.

\section{Procedure}

The contaminated atmosphere is drawn through the filter by means of the hand pump at about the rate of 1 stroke in 5 seconds. If concentrations are known to be high, 30-50 strokes are taken, but if concentrations are low, 100 or even 150 strokes may be necessary. After the sample has been taken the naphthalene filter is carefully loosened from the sinter with a spatula and is dropped into a test-tube ( 6 in. by 0.75 in.). It will be found that the naphthalene comes away almost com- pletely from the micro filter and the small crystals remaining can be carefully scraped into the test-tube; 10 c.c. of the solvent are now added and the tube shaken to assist the solution of all the naphthalene. To this is now added 0.5 c.c. of 10 per cent. $\mathrm{KOH}$ and the tube shaken again. The time of the addition of the alkali is noted and, 10 minutes after this, the colour which develops is matched against the standards.

From the table which follows, an estimation of the concentration can readily be made. This table holds only provided the pump is of $125 \mathrm{ml}$. capacity.

As this method only takes account of the 2:4 DNT present, it is desirable in most cases to add 25 per cent. to the figure obtained to give total DNT.

TABLE 4

MILLIGRAMS DNT/CUBIC METRE FOR PUMP CAPACITY $125 \mathrm{ML}$.

\begin{tabular}{c|r|r|r|r}
\hline $\begin{array}{c}\text { Number } \\
\text { of } \\
\text { strokes }\end{array}$ & \multicolumn{4}{|c}{ Colour standard } \\
\cline { 2 - 4 } & 1 & 2 & 3 & 4 \\
\hline 30 & $8 \cdot 0$ & $17 \cdot 0$ & $25 \cdot 0$ & 33 \\
50 & $5 \cdot 0$ & $10 \cdot 0$ & $15 \cdot 0$ & 20 \\
100 & $2 \cdot 5$ & 5.0 & $7 \cdot 5$ & 10 \\
150 & $1 \cdot 7$ & 3.4 & $5 \cdot 0$ & 7 \\
\hline
\end{tabular}

\section{Summary}

Airborne TNT and tetryl are estimated colorimetrically in situ by absorption of the material in a mixed solvent of methyl ethyl ketone and cyclohexanone to which a little potassium hydroxide solution has been added. Rapid assessment of the results is obtained by using a comparator and a special Tintometer disc.

Airborne DNT is absorbed in a naphthalene filter which is then dissolved in acetone and cyclohexanone containing potassium hydroxide. The colour projuced is matched against aqueous standards containing Gentian violet.

\section{Acknowledgment}

This paper is published with permission of the Ministry of Supply.

\section{REFERENCES}

Briscoe, H. V. A. (1939). J. roy. Soc. Arts, 88, 104.
Channon, H. J., Mills, G. T., and Williams, R. T. (1944). Biochem.

J., 38, (1), 70. Gov. Ted Bull, Wash 41, 219

Goldman, F. H., and Rushing, D. E. (1943). J. industr. Hyg., 25, 164.

Kay, K. (1941). Canad. J. Res., (B) 19, 86.

Pinto, S. S., and Fahy, J. P. (1942). J. industr. Hyg. 2424. 